\title{
Provisão para créditos de liquidação duvidosa e controles de limites de solvência em instituições bancárias no Brasil
}

\author{
Provision for dubious settlement credits and control of solvency limits in banking \\ institutions in Brazil
}

Provisión de créditos dudosos de liquidación y control de límites de solvencia en instituciones bancarias en Brasil

\section{Antonio Lopo Martinez}

Doutor em Contabilidade na Universidade de São Paulo (USP)

Doutorando em Direito na Faculdade de Direito da Universidade de Coimbra

CP: 3004-528 - Coimbra - Portugal

Telefone: +351 $239859802 / 01$

E-mail: antoniolopomartinez@gmail.com

\section{Acione de Souza Loose}

Mestre em Contabilidade Fucape Business School (FUCAPE)

Gerente Geral do Banco do Brasil

Endereço: Av. Fernando Ferrari, 1358

CEP: 29075-053 - Vitória/ES - Brasil

Telefone: (27) 40094444

E-mail: souzaloose@yahoo.com.br

Artigo recebido em 17/02/2018. Revisado por pares em 09/04/2018. Reformulado em 15/04/2020. Recomendado para publicação em 15/04/2020 por Carlos Eduardo Facin Lavarda (Editor-Chefe). Publicado em 24/04/2020. 


\section{Resumo}

Este estudo teve como objetivo verificar como a Provisão para Créditos de Liquidação Duvidosa pode ser influenciada pelo nível de capital regulatório nas instituições bancárias no Brasil para manter seu limite de solvência, o Índice de Basiléia. E ainda, verificar se existe uma motivação para Income Smoothing, Gerenciamento de Resultado. Foram utilizados os dados de 115 instituições financeiras bancárias situadas no Brasil divulgado pelo Banco Central do Brasil (BACEN) nos anos de 2010 a 2016. De maneira geral, as análises ilustram que, o Resultado das operações de crédito explica uma elevação nas provisões para créditos de liquidação duvidosa, porém a análise não apontou que a Provisão de Crédito para Liquidação Duvidosa esteja sendo gerenciada em função dos níveis de capital regulatório. O modelo não evidenciou que o volume de Provisão de Crédito para Liquidação Duvidosa esteja relacionado ao montante de capital das instituições financeiras bancárias do Brasil.

Palavras-chave: Provisão para créditos de liquidação duvidosa; Regulação bancária; Gerenciamento de resultado

\section{Abstract}

This study aimed to verify how the provision for dubious settlement credits can be influenced by the level of regulatory capital in banking institutions in Brazil to maintain its solvency limit, the Basel index. And, check if there is a motivation for income smoothing, earnings management. The data of 115 financial institutions located in Brazil were used by the Central Bank of Brazil (BACEN) in the years 2010 to 2016. In general, the findings illustrate that, the result of credit operations explains a rise in provisions for dubious settlement credits, but the analysis did not point out that the provision of credit for dubious settlement is being managed in function of regulatory capital levels. The model did not demonstrate that the volume of credit provision for dubious settlement is related to the amount of capital of the banking financial institutions of Brazil. Keywords: Provision for dubious settlement credits; Banking regulation; Earnings management

\section{Resumen}

Este estudio procuró verificar cómo la provisión para créditos dudosos de liquidación puede ser influenciada por el nivel de capital regulatorio en las instituciones bancarias en Brasil para mantener su límite de solvencia, el índice de Basilea. Y también, comprobar si hay una motivación para suavizar los ingresos, la gestión de resultados. Los datos de 115 instituciones financieras bancarias ubicadas en Brasil fueron utilizados por el Banco Central de Brasil (BACEN) en los años 2010 a 2016. En general, el análisis ilustra que, el resultado de las operaciones de crédito explica un aumento de las provisiones para créditos dudosos de liquidación, pero el análisis no señaló que la provisión de crédito para la solución dudosa se está gestionando en función de los niveles de capital regulatorio. El modelo no demostró que el volumen de la provisión de crédito para un arreglo dudoso esté relacionado con la cantidad de capital de las instituciones financieras bancarias de Brasil.

Palabras clave: Provisión para créditos dudosos de liquidación; Regulación bancaria; Gestión de resultados

\section{Introdução}

As instituições financeiras ao atuarem como intermediadores financeiros podem afetar os setores da economia causando impactos substanciais em seu desenvolvimento social, econômico e em sua estabilidade. Originam-se destes fatores a preocupação com relação à estabilidade do Sistema Financeiro (CARDOSO, 2016).

Elas possuem regulamentação própria. No Brasil seguem as diretrizes e normas de seu órgão regulador, o Banco Central do Brasil (BACEN). Em 1994, Visando disciplinar o sistema 
financeiro nacional, aderiu ao Acordo de Basiléia I de 1988. Tais medidas tinham por objetivo proporcionar maior estabilidade e solidez ao mercado bancário e a economia do país como um todo (SCHLOTTFELDT, 2004).

Assim, o Conselho Monetário Nacional (CMN) instituiu um requerimento mínimo de capital 8\% de seus ativos ponderados pelo risco, Resolução 2.099, de 17/08/1994. Em 1997 como medidas de ajuste, este índice foi elevado para 10\% (Circular 2.784 de 27/11/1997) e alterada sua forma de cálculo por meio da mesma circular (FURTADO, 2005).

Também foram estabelecidos dois modelos contábeis (obrigatórios) para apresentação das demonstrações contábeis: o Plano Contábil das Instituições Financeiras atuantes no Sistema Financeiro Nacional (COSIF) e o instituído pelo órgão International Accounting Standards Board (IASB). Ambos os modelos tratam da constituição da PCLD (CARDOSO, 2016).

A partir da divulgação de resultados das instituições financeiras bancárias no Brasil o objetivo deste trabalho foi verificar se as Despesas com Provisão para crédito de Liquidação Duvidosa (PCLD) são influenciadas em função da manutenção do Índice de Basiléia através dos dados divulgados pelo COSIF utilizando-se o modelo de Fuji (2004), que visou testar o gerenciamento de resultados e capital, ou ambos, em instituições financeiras bancárias. E ainda verificar a existência de uma motivação para o "gerenciamento de resultado".

Neste sentido, de acordo com Greenawalt e Sinkey (1988) a esse comportamento, denomina-se income smoothing, manipulação do resultado visando atender o interesse dos administradores. Utilizou-se os dados das maiores instituições financeiras bancárias do país divulgadas pelo BACEN nos anos de 2010 a 2016. O período foi escolhido, devido ao fato de ser posterior a crise do sistema financeiro de 2008, e compreenderam as alterações do Acordo de Basiléia (I e II), e ainda, ser intercalado com os ajustes que devem ser feitos até 2018 pelo Acordo de Basiléia III.

Isto posto, o objetivo desta pesquisa é verificar como a Provisão para Créditos de Liquidação Duvidosa pode ser influenciada pelo nível de capital regulatório nas instituições bancárias no Brasil assegurando a manutenção do seu limite de solvência, o Índice de Basiléia. E adicionalmente, verificar se existe uma motivação para Income Smoothing, isto é gerenciamento de resultados para reduzir a variabilidade dos resultados contábeis.

A relevância deste trabalho se deve ao fato de que fragilidades no sistema financeiro bancário podem comprometer a economia em escala global, se fazendo, portanto necessário o acompanhamento rigoroso do capital e de sua solidez. Assim, este estudo poderá auxiliar com novas evidências sobre o desempenho das instituições financeiras bancárias, a partir das mudanças trazidas pela Resolução CMN n ${ }^{\circ}$ 2.682, de 21.12.99, principalmente quanto a PCLD e a classificação de risco das operações de crédito. Almejou, ainda, contribuir com estudos sobre o índice de capital dos bancos e as implicações da PCLD em sua composição e fornecer informações sobre o sistema financeiro quanto da implantação dos Acordos de Basiléia.

No restante do artigo será exposto a fundamentação teórica, discutindo e apreciando os principais temas associados, proximamente, ao objetivo da investigação. Na sequência é exposta a metodologia discorrendo sobre modelo econométrico e testes empregados para sustentar os resultados da pesquisa. A partir desse ponto, apresentam-se os resultados e as implicações dos mesmos. A pesquisa encerra-se com a exposição das conclusões da investigação.

\section{Fundamentação Teórica}

\subsection{Aspectos do Sistema Financeiro}

Através do I Acordo de Basiléia de 1988, o setor financeiro bancário se tornou objeto de estudos de grande relevância para a manutenção de mercados estáveis. Constatou-se empiricamente a existência de uma afinidade positiva, responsável por ligar o desenvolvimento do 
sistema financeiro e crescimento econômico devido a sua estreita relação com a circulação de dinheiro na economia (ARAÚJO, 2008).

As Crises financeiras internacionais dos mercados bancários deixaram os países em uma situação de alerta. As Crises do México (1982) e o Black Monday da Bolsa de Nova Iorque (1987), principais bancos centrais do mundo, provocaram revisões nas regras de supervisão bancária, fazendo com que surgissem questionamentos sobre a estabilidade econômica dessas instituições (COSTA, 2004).

Tais questionamentos fizeram com que se estabelecessem padrões mínimos de estabilidade para os bancos. Assim, o Bank for International Settlements (BIS), por meio do Acordo de Capital de Basiléia I. O Acordo objetivava proporcionar maior clareza, estabilidade e segurança às transações financeiras aos bancos internacionais (RODRIGUES, 1998).

Assim, deliberou sobre três conceitos: o de Capital Regulatório, que seria o montante de capital próprio reservado para a cobertura de riscos; o de Fatores de Ponderação de Risco dos Ativos, onde se definiu que a exposição ao risco de crédito dos ativos, tanto dentro como fora do balanço, seria medida com base em diferentes pesos, levando em consideração o perfil do tomador do crédito; e o terceiro, o Índice Mínimo de Capital para Cobertura do Risco de Crédito, ou seja, o Índice de Basiléia (IB), como sendo o quociente entre capital regulatório e ativo ponderado pelo risco (MARQUES et al., 2013).

Já no que se refere ao Brasil, sua adesão ao Acordo, a partir de 17 de agosto de 1994, com a publicação da Resolução do CMN de nº 2.099. De 1988 a 1998 houve um declínio na quantidade de instituições bancarias no país, principalmente a partir de 1994 quando se deu a assinatura do Acordo (PUGA, 1999).

A adesão do Brasil ao Acordo foi considerada um balizador para o sistema financeiro do país, a Resolução 2.099, de 17/08/1994 o BACEN, instituiu um novo conceito de regulação prudencial para as instituições. Inicialmente se estabeleceu um requerimento mínimo de capital com um valor mínimo de $8 \%$ entre o Capital Base (Patrimônio de Referência - PR) e os ativos ponderados pelo risco conforme a regulamentação em vigor (Patrimônio Líquido Exigido - PLE), índice alterado posteriormente (SANTOS, 2007).

Visando corrigir algumas falhas identificadas no Basiléia I, em 2004 se instituiu o Acordo de Basiléia II e em 2010, o Acordo de Basiléia III. Entretanto, as orientações referentes aos dois acordos, deviam ser consideradas em conjunto, conforme divulgado por meio do Comunicado BACEN nº 20.615/2011 (BRITTO et al., 2013).

Os Acordos visavam sobre a adequação de capital e a criação de mecanismos de controle aos quais os órgãos supervisores deveriam recorrer para manter a solidez das instituições bancárias. No entanto, ainda existiam dificuldades em se estimar o montante de capital capaz de suportar as prováveis perdas na realização de seus negócios. Assim, o cálculo para a constituição das Provisões de Crédito para Liquidação Duvidosa impacta o desempenho e a estrutura financeira da empresa, modificando as percepções de mercado quanto ao risco. Por serem subjetivos, esses cálculos, propiciam aos gestores dos bancos utilizá-las para gerenciar seu resultado. Podem, por exemplo, realizar concessões de créditos com altos riscos, com o intuito de alavancar sua carteira de crédito, aumentando assim suas provisões para futuramente divulgar resultados satisfatórios (RODRIGUES, 1998).

Logo, a constituição da PCLD, é responsável por assinalar o grau de exposição de risco da instituição. E informa também o quanto de seu patrimônio líquido teria que ser destinado para se evitar a insolvência. Assim, a PCLD, atua como componente balizador na composição dos Îndices de Requerimento de Capital, das instituições financeiras. (CERQUEIRA, 1998).

\subsection{Regulação Bancária}

A regulação prudencial foi responsável por uma das alterações fundamentais verificadas 
nas instituições financeiras bancárias. A mudança no conceito estabeleceu requisitos mínimos de capital tendo por base os diferentes riscos que podiam acometer as instituições financeiras em suas transações, principalmente no que se refere aos riscos das operações de crédito (MICCA, 2003).

De acordo com Soares (2001), a instituição de um capital mínimo para os bancos proporcionado pelo Acordo de Basiléia I foi o que possibilitou o controle de Capital. Seu controle seria uma medida para fazer frente ao surgimento de crises no sistema financeiro (SOARES, 2001).

Embora após a assinatura do Acordo, tenham ocorrido desastres financeiros que abalaram o sistema financeiro internacional como o dos bancos Daiwa Bank (1995) e Barings Bank (1995, o acordo anterior serviu de base para novas ações. Houve necessidade de criação de novo parâmetro para cálculo do valor de capital, e de mecanismos que coibissem o risco operacional a que as instituições estavam sujeitas, surgindo então o The New Basel Capital Accord, ou "Novo Acordo da Basiléia" (TRAPP; CORRAR, 2005).

Assim, em junho de 2001 começou a se debater uma nova proposta com a finalidade de revisar o Acordo de Basiléia I de 1988 e desenvolver uma estrutura que fortalecesse ainda mais a solidez e a estabilidade do sistema bancário internacional. Sem, no entanto, interferir na concorrência entre os bancos (ERNST; YOUNG, 2004).

De acordo com Mendonça e Andrade (2006) o Comitê da Basiléia utilizou a justificativa de que o acordo original não propiciava estímulo para a elaboração de métodos internos de avaliação de riscos e nem possuía técnicas diversas que permitissem sua atenuação para realizar sua revisão. A revisão manteve a exigência de um capital mínimo, porém com maior complexidade. Porém deveriam manter uma relativa flexibilidade, com relação aos riscos adquiridos pelas instituições bancárias. O capital mínimo passou a ser regulado e sofrer controle das autoridades de supervisão e dos agentes do mercado. O Basiléia II foi dividido em três pilares: Pilar 1: compreende a exigência de requerimentos mínimos de capital; Pilar 2: compreende o processo de supervisão bancária; e o Pilar 3: compreende a disciplina de mercado.

Foram introduzidos avanços que permitiram a adoção de técnicas de mensuração de risco de crédito: o método padronizado e os métodos internos Internal Rating Based (IRB) básico e avançado. E a partir de então a avaliação de risco de crédito das instituições passou a ser realizada por entidades externas responsáveis por classificar e definir os riscos (CARNEIRO, 2002).

Primordialmente se objetivava a estabilidade do sistema via regulação prudencial, porém não se evitou o surgimento das crises. E embora se tenha atribuído a crise de 2008, como sendo consequência de algumas deficiências do Acordo de Basiléia II, se suas medidas não tivessem sido adotadas poderia ter havido um comprometimento ainda maior da funcionalidade do sistema de forma a afetar também o crescimento econômico (ERNST; YOUNG, 2004).

No que se refere ao Brasil, foram instituídos por intermédio da Resolução 2.099/94 que teve por intuito instituir a constituição e origem do capital regulatório. Assim, se definiu que as instituições financeiras autorizadas a operar no Brasil deveriam calcular o capital exigível (PLE), com razão de capital-ativo igual a 0,08 e alavancagem de 12,5. Sendo que, esses valores foram alterados sucessivamente em junho 1997 (Resolução no 2 399) para 0,10; e, em novembro de 1997 para 0,11 (Circular $\mathrm{n}^{\circ}$ 2.784). Havendo assim, redução da capacidade de alavancagem dos bancos de 12,5 para, respectivamente, 10 e 9,09 vezes seu patrimônio líquido (RODRIGUES, 1988).

\subsection{A Regulação dos Bancos no Brasil, Capital e Risco}

Os fatos ocorridos nas instituições financeiras internacionais provocaram repercussões em diversos países do mundo, inclusive no sistema bancário brasileiro. Assim, se tornou latente a convergência da legislação brasileira aos padrões e normas internacionais, visando à uniformidade e adequação ao sistema financeiro mundial. Dessa forma, torna-se necessário tecer um esboço dos principais acontecimentos provenientes desta mudança no Brasil (SCHLOTTFELDT, 2004).

Em agosto de 1994 o Brasil aderiu ao Acordo da Basiléia e divulgou a Resolução nº 2.099 
pelo BACEN. A base de cálculo do Capital Regulatório foi alterada. Com a aderência ao Acordo de Basiléia, foram excluídas as provisões para créditos de liquidação duvidosa da estruturação do Capital Nível I, e a inclusão de reserva para provisão passou a ser limitada a 1,25\% dos ativos ponderados ao risco, no que se refere ao Capital Nível II (SANTOS, 2007).

Já, no que se refere à avaliação de risco das operações de crédito, as instituições bancárias deveriam utilizar as diretrizes estabelecidas pela Resolução CMN n ${ }^{\circ}$ 2.682, de 21 de dezembro de 1999. Esta resolução foi editada com a finalidade de definir critérios mais amplos para a constituição da PCLD, sendo que para a classificação das operações de créditos definida em níveis de risco (SILVA, 2013).

Em $1^{\circ}$ de março de 2013, foram editadas as Resoluções CMN n. 4.192 e 4.193, onde o BACEN publicou novas disposições sobre o patrimônio de referência e consonantes a apuração da exigência de requerimentos mínimos de capital. O Acordo de Basiléia III definiu um fator de risco para as instituições financeiras dentro do percentual de $11 \%$, sendo que, no ano de 2019, este será ajustado aos parâmetros do BCBS (SANTOS, 2007).

Observou-se que as principais mudanças até então adotadas, envolveram aspectos relacionados ao capital, a solidez, a estabilidade financeira e o risco. Essas alterações resultaram em mudanças na composição das Provisões para Créditos de Liquidação Duvidosa, pois estas afetam os mecanismos de composição de capital. Então, o BACEN instituiu regras semelhantes às do BCBS, tendo em vista a maior parte dos créditos tributários originados pelos bancos brasileiros é decorrente da PCLD. A subtração desses créditos do Capital Regulatório pode provocar uma desvantagem competitiva entre os bancos brasileiros e os estrangeiros (PINHEIRO, et al. 2015).

Collins et al. (1995) assinala que as operações de crédito são relevantes para a Constituição da PCLD, pois está é componente na formação do resultado. Devido a sua representatividade no capital, créditos baixados como prejuízos podem ser utilizados como forma de gerenciar capital regulatório, pois podem influenciar no cálculo do resultado.

Da mesma forma, segundo, Kim e Kross (1998) os bancos com menor índice de capital regulatório podem elevar os créditos baixados como prejuízos e diminuir as provisões de perdas com empréstimo no intuito de atingir o índice. Portanto, agindo assim, os administradores dos bancos com menor índice de capital regulatório podem se valer da discricionariedade para gerenciar o capital regulatório.

Segundo Shrieves e Dahl (1992) outra possível explicação para o fato de se ter um elevado nível de capital e risco seria o fato de existirem variáveis que são estratégicas, de fatores exógenos e endógenos, que podem exercer influência no ajustamento de capital e de risco nos bancos. Assim, quando considerados podem explicar a existência de manutenção de mais capital do que é exigido e a elevação dos níveis de risco.

Para Andrade (2014) o Índice de Alavancagem instituído pelo Acordo de Basiléia III, surgiu como um instrumento capaz de interferir tanto no risco como na regulação do capital, sendo que para fins de ajuste entre capital e risco instituiu-se que até 2018 o índice de alavancagem será de 3\%, devendo ser adicionado ao Pilar 1. Enquanto que o Índice de Basiléia de $11 \%$ que mede o nível de capital regulatório para os bancos será alterado gradativamente até o valor de $13 \%$.

\subsection{Provisão para Créditos de Liquidação Duvidosa - PCLD}

De acordo com Fernandes et al. (2008) a constituição da PCLD é a provisão mais comum na contabilidade financeira, no entanto, representa em qualquer empresa uma estimação da perda provável na realização dos créditos. Seu cumprimento deve se ater aos Princípios Fundamentais de Contabilidade, principalmente na Efetivação da Receita e Comparação com a Despesa.

Desta forma a PCLD tem sido ao longo dos anos objeto de estudos e críticas pela forma que é estimada. São estabelecidas tendo por base o montante de crédito concedido e a probabilidade de não recebimento dos ativos financeiros. Quando realizada incorretamente 
compromete a qualidade da carteira de crédito, podendo apresentar resultados equivocados sobre a estabilidade e solidez da empresa ao mercado (NIYAMA; GOMES, 2005).

De acordo com Greenawalt e Sinkey (1988), a esse comportamento adotado dá-se o nome de "income smoothing" (gerenciamento de resultados). Pois, a constituição da PCLD tende a atuar como um "aparelho" de suavização por valer-se da discricionariedade em seu cálculo. Os bancos realizam provisões, em sua maioria, superiores ao mínimo regulamentar, quando os seus lucros bancários se apresentam mais elevados, com o objetivo de criar "reserva" para datas futuras em que o lucro se apresente menor. Atitude, portanto, caracterizada como técnica de suavização de resultado. Desta forma, se observa que se estabelece assim, uma relação positiva entre resultado e PCLD.

Neste sentido a Resolução 2.682 de 1999, instituiu melhorias na forma de medir o risco de crédito, o cálculo do ativo ponderado pelo risco e do patrimônio líquido exigível. Essa Resolução definiu aspectos relacionados ao devedor e seus garantidores, a situação econômico-financeira; o grau de endividamento; a capacidade de gerar resultados dentre outros. E também a obrigatoriedade de que os níveis de classificação de risco fossem revistos mensalmente, na realização dos balancetes e balanços, se observando o atraso verificado no pagamento da parcela principal ou de seus encargos (MARQUES, 2002).

Logo, a PCLD compõe a análise dos resultados, que envolve risco de crédito e estabelece afinidade entre o evento de default e sua situação econômico-financeira. Os resultados apresentados por meio de suas demonstrações contábeis e financeiras são utilizados como base para o cálculo do Índice de Basiléia, permitindo assim classificá-las como prováveis solventes ou insolventes (BRITTO, 2008).

Devido a isto, o BACEN estabeleceu dois modelos contábeis para evidenciação do risco de crédito dentro das demonstrações contábeis: o modelo brasileiro, do Plano Contábil das Instituições Financeiras atuantes no SFN (COSIF) e o modelo tratado pelo órgão International Accounting Standards Board (IASB). O primeiro chamado de perdas esperadas estabelece a classificação das operações de crédito dentro de níveis crescentes de risco (de AA a H), definindo para cada nível de classificação um percentual de provisionamento para potenciais perdas como apresentado anteriormente. Já o segundo, de perdas incorridas, tem por base as previsões definidas pela IFRS, definidas pelo IAS 39. Neste a PCLD é estabelecida a partir da probabilidade de não cumprimento das obrigações por parte das contas a receber, sendo que a provisão deve ser suficiente para suprir as perdas na cobrança dos valores.

As normas internacionais de divulgação financeira IFRS consideram que os empréstimos concedidos e os recebíveis são considerados ativos financeiros e desta forma devem ser avaliados por meio do custo amortizado, e ainda ao término de cada período o valor deve ser reavaliado e ajustado para contagem de eventuais perdas por diminuição no valor recuperável, ou seja, impairment (SILVA, 2013).

\subsection{Gerenciamento de Resultado}

O tema de Gerenciamento de Resultados ou "income smoothing" sob a perspectiva da PCLD, se torna um componente de suma importância para constituição do resultado financeiro das instituições. As provisões atuam como sendo responsáveis por estimar o risco da carteira de crédito de influenciando seu resultado. Ademais, considera-se que a qualidade da carteira de crédito, é de fundamental importância para se gerenciar o risco de crédito do sistema financeiro. (FERNANDES et al., 2008).

Segundo Bischoff (2012), a escolha de critérios para a apresentação das informações contábeis possibilita a prática de gerenciamento de resultado, o que enseja apreensão, pois a manipulação dos dados pode não representar a fidedignidade dos resultados contábeis divulgados por parte das empresas. 
Para Martinez (2008), assim como Bischoff, (2012), existem fortes evidências de que as empresas brasileiras "gerenciam" seus resultados. O intuito seria o de se evitar a reprodução de perdas, e de sustentar um desempenho recente, para isto se valeria, portanto, de piorar o resultado atual a fim de garantir resultados futuros. Assim, como descrito por Friedman e Roberts (1983), há uma manipulação dos dados da provisão para perdas, visando a atenuação do resultado, com a finalidade de que a empresa não incorra em processo de perdas extremas em dado período.

No arcabouço teórico os autores apresentam considerações positivas e negativas com relação ao gerenciamento de resultado por meio da PCLD. Por exemplo, Laeven e Majnoni (2003), defendem a ideia de que estas devem ficar livres para que se movimentem ao longo do ciclo econômico, estabelecendo-se requisitos mínimos regulatórios e por um prazo estipulado. Assim, a suavização do resultado, atuaria, reduzindo a variabilidade dos lucros e preservando o capital dos bancos. Porém, reconhecem que ao mesmo tempo, a "suavização do resultado" tem conotações negativas, pois introduz alterações no lucro das empresas, visando atender interesses pessoais dos gestores, para manter resultados satisfatórios para o acionista.

Neste sentido Bornemannet al. (2012), pondera que a utilização do gerenciamento de resultado por meio da PCLD pode não ser benéfica, por considerar perdas presumidas. Não devendo esta ser utilizada para a suavização de resultado, pois pode distorcer as informações divulgadas aos investidores por não refletir a situação real da empresa.

Segundo a análise de Holanda e Coelho (2013), o gerenciamento de resultado, possibilita um problema de agenda, onde a relação de agência se encontra na possibilidade de o agente assumir uma conduta oportunista. Uma notícia contábil de qualidade poderá ser um importante instrumento para monitorar conflitos de agência e transmitir com eficácia a situação econômica das firmas a seus investidores. Já o contrário, pode encobrir atitudes oportunistas dos gerentes das firmas, causando prejuízo dos demais stakeholders.

Fuji (2004), concorda com Laeven e Majnoni (2003), no sentido de considerar que, o gerenciamento de resultado pode ser benéfico a empresa, possibilitando que se gerencie riscos que podem ser apenas momentâneos, não sendo prejudicial aos interesses do negócio. Assim, os gestores poderiam suavizar os resultados, como forma de redução da volatilidade dos lucros evitando que tal variação possa ser interpretada como elevação de risco da firma.

Goulart (2007) exemplifica neste sentido, que no caso de operações de crédito, quando o lucro (extraído o resultado da despesa de PCLD) aumenta, há probabilidade de que está haja no sentido de diminuí-lo; logo se o lucro se reduz, ocorre a possibilidade de que se postergue o apontamento de provisões, de modo o resultado seja impactado de maneira menos adversa. Há indícios de que bancos com boa performance no momento presente e com um mau desempenho projetado, postergam divulgação de lucros utilizando-se da diminuição do lucro corrente por meio da PCLD. Já os com bom desempenho corrente e boa projeção futura, se têm evidências de que transferem de lucros futuros para o presente por meio da PCLD, utilizando-se de accruals discricionários para a prática de suavização de resultados.

Ainda, como motivação ao Gerenciamento de Resultados de forma contínua, Burgstahler e Dichev (1997), considera ser a não divulgação de resultados com prejuízos, sua principal causa. Devido ao fato de transmitir um sinal de desempenho improdutivo, seria benéfico então, divulgar um resultado que evidencie lucro.

Nesse sentido, Degeorge, Patel e Zeckhauser (1999) ponderam que uma propensão a queda de resultados, ainda que insignificante, apresenta um fator de instabilidade, ou seja, um ponto negativo, especialmente para empresas com expectativas de forte crescimento. Empresas de alto valor de mercado em relação ao valor patrimonial são compreendidas pelo mercado como hábeis para crescer. Nesta conjuntura, acredita-se que para esse tipo de empresa existe um estímulo em apostar em mecanismos que impeçam a queda do resultado, com a finalidade de manter o desempenho presente, logo, apresentam tendência para gerenciar seu resultado.

Para Edgard e Kelly (2015), a técnica de gerenciamento de resultados esta alicerçada pelo 
nível de PCLD, pois está se situa entre as escolhas que poderiam ser feitas, e ainda, impactar o resultado contábil. Assim, devido ao fato da PCLD representar de modo geral, as contas regularizadoras das instituições financeiras, são de fundamental importância nas deliberações dos gestores para manipulações contábeis, são, portanto, o alvo dos reguladores em termos de gerenciamento de resultado.

\subsection{Provisão para Créditos de Liquidação Duvidosa (PCLD) - O Modelo Cosif e as alterações propostas pelo Modelo IFRS de Impairment}

As instituições bancárias devem obedecer a dois tipos de deliberações normativas para constituição da PCLD. Os modelos de demonstrações financeiras são ordenados com base na regulamentação específica, instituída pelo $\mathrm{CMN}$, e nas normas internacionais IFRS, elaboradas pelo IASB, no entanto diferem em relação ao momento em que irão tratar o reconhecimento das despesas com provisões (CARDOSO, 2016).

Assim, quando tratado sob a ótica das normas internacionais IFRS, os empréstimos concedidos e recebíveis correspondem a ativos financeiros e necessitam ser aferido pelo custo amortizado. Vale lembrar, que ao final de cada período esse valor deve ser reanalisado e ajustado de forma a ser possível calcular eventuais perdas por diminuição no valor recuperável, ou seja, impairment. Já no modelo COSIF a provisão é realizada no começo de cada exercício como proteção para que a instituição com relação às perdas financeiras decorrentes da análise do risco de crédito de suas operações (SILVA, 2013).

Tendo por base o modelo COSIF, no Brasil houve alterações para cálculo da PCLD estabelecidas pela Resolução CMN n 2.682/1999. Essas alterações, segundo Niyama (2001), promoveram o fortalecimento e uma responsabilidade maior das áreas que cuidam do crédito nas instituições financeiras. Através dela foram estabelecidas políticas e normas para se conceder crédito com direcionamentos definidos por bases técnicas. Esse fato possibilitou a obtenção de uma divulgação mais clara sobre a qualidade da carteira de crédito das instituições, sendo possível detalhar os riscos que lhe foram atribuídos. No entanto, os administradores não deixam de ser responsáveis por manter a PCLD em um nível compatível com a legislação.

Niyama e Gomes (2005) destacam ainda como regras fundamentais de constituição da PCLD a obrigatoriedade da transferência de operações não liquidadas na data acordada para créditos com atraso e em liquidação, com base em prazos de 60 a 360 dias. Assim, as instituições financeiras autorizadas pelo BACEN a funcionar no Brasil necessitam classificar as operações de crédito, em ordem crescente de risco, de AA, A, B, C, D, E, F, G e H e dentro dos percentuais exigíveis para cada nível de atraso.

Segundo Santos (2007), com base no modelo COSIF há a antecipação da provisão tendo por meio da classe de risco do cliente. Classe esta, que é definida pela própria instituição financeira no momento da concessão do crédito. Porém em caso de inadimplência pode haver aumento das provisões. Assim, os níveis de risco devem ser revisados mensalmente, no momento da elaboração dos balancetes e balanços, considerando o atraso verificado em pagamentos da parcela do principal ou de seus encargos.

Já de acordo com a metodologia do International Accounting Standard (IAS) 39, os ativos financeiros classificam-se em: ativos financeiros com avaliação a valor justo e com ajuste no momento do resultado; ativos financeiros que devem ser mantidos até o vencimento; operações de créditos e recebíveis; e ativos financeiros a disposição para venda.

Desta forma, a norma internacional estabelece que a primeira avaliação de ativos financeiros seja apurada pelo valor justo, o que, na maioria das vezes, representa o valor da negociação acrescido dos custos de sua transação. Assim, os custos inerentes a transação não fazem parte do valor justo do ativo, sendo necessário o seu reconhecimento diretamente no momento da apuração do resultado. Não se consideram as perdas baseadas em eventos futuros, 
porém, no que se refere ao Sistema Financeiro Nacional (SFN), a regulamentação aplicável são as normas do CMN e do BACEN (SILVA, 2013).

Embora o modelo IFRS de provisionamento embasado em perdas incorridas tenha sido criticado e apontado como justificativa para a descontinuidade operacional das instituições financeiras nos Estados Unidos e o agravamento da crise financeira internacional de 2008. Em termos contábeis, o cálculo realizado por este modelo, revelou a existência de pontos fracos nos relatórios financeiros baseados no reconhecimento tardio de perdas (impairment). Verificou-se que o modelo demonstrou grande vulnerabilidade em ambientes econômicos instáveis, assim o International Accounting Standards Board (IASB) propôs mudanças no tocante ao reconhecimento de perdas em ativos financeiros. Reformulando-se, assim, parte da IAS 39 o que deu origem a IFRS 9 (CANECA, 2015).

Por este motivo, a IFRS 9 com vigência a partir de 2018, fez recomendações de mudanças com relação ao modelo de estimação de perdas, onde se deveriam utilizar as perdas esperadas em vez de perdas incorridas. A nova resolução prevê que a provisão de perdas prováveis para o período de 12 meses, caso o risco de crédito aumente significativamente, deverá ser estimada compreendendo toda a vida da carteira de empréstimos. Assim sendo, as provisões para impairment de ativos financeiros tenderão a aumentar e, como formas de absorção das perdas podem alterar as estratégias, aumentando assim o preço dos empréstimos e encurtando o tempo de liquidação do contrato (FURTADO, 2005).

Assim, houve a reformulação do Acordo de Basiléia II, que vigorava até o momento da crise, dando origem ao Acordo de Basiléia III, onde foram estabelecidas medidas complementares no intuito de resguardar a solidez e estabilidade do sistema bancário evitando uma crise sistêmica. Houve aumento da exigência de capital dos bancos com aumento da regulação bancária (BRITTO et al., 2013).

\subsection{As Mudanças Introduzidas pelo Acordo de Basiléia III}

A instituição dos Acordos de Basiléia I, II e III se constituiu em bases fundamentais para a regulação financeira representando um avanço para manter sua solidez. Os sistemas financeiros tem se constituído em um desafio para aqueles que analisam e estudam o patrimônio dos bancos. A aplicação de normas mais rigorosas tende a evitar ou pelo menos restringir de maneira drástica o risco de uma falha nesse sistema (BRITTO et al., 2013).

Embora representem um marco para o sistema financeiro bancário, de acordo com Martin (2006), o Acordo de Basiléia I ganhou críticas por ter sido avaliado como arbitrário. Negligenciou a correlação existente entre os ativos, não considerou a exposição dos bancos aos riscos de mercado, operacional, de liquidez e legal. Essas críticas induziram ao Acordo de Basiléia II em 2004, que foi quando o Comitê de Basiléia instituiu alterações e vez revisões no acordo anterior (FURTADO, 2005).

Com relação ao Basiléia II, Carvalho (2010) pontua que a crise vivenciada em vários países em 2007 permitiu se detectasse a necessidade de ajustes para preservação do mercado. A falência do banco, Lehman Brothers em 2008, fez com que o Comitê de Basiléia implementasse alterações e um novo acordo.

Até, então se acreditava que as medidas estabelecidas poderiam garantir a estabilidade do mercado. Porém, a Crise de 2008 foi atribuída às inovações financeiras, de uma deficiente regulação do sistema em conjunto com o arcabouço prudencial. E assim, no intuito de corrigir as falhas detectadas, instituiu-se o Acordo de Basiléia III, um conjunto de medidas complementares, adotadas a fim de preservar a solidez e estabilidade do sistema bancário (ANDRADE, 2014).

Foram introduzidos os conceitos de "capital conservation buffer" ou capital complementar; o "countercyclical buffer" ou Capital Contracíclico, que tinha por objetivo garantir a estabilidade econômico-financeira, conferindo certa liberdade aos bancos centrais. Pois, em tempos de não 
crise, formaria um colchão de capital para suprir as perdas nos momentos de crise. Foram estabelecidos também, índices mínimos de liquidez e uma taxa máxima para a alavancagem. Portanto, as alterações consistiam na correção das medidas do Basiléia II, que foram consideradas insuficientes (PINHEIRO et al., 2015).

O novo Acordo de Capital, o Basiléia III, foi mais rigoroso que o anterior, pois passou a contemplar a soma dos seguintes elementos: O Capital Nível 1 - com 6\% dos Ativos Ponderados Pelo Risco (APR) + Capital Principal (maior ou igual a 4,5\% de APR) e Capital Complementar; e o Capital Nível 2 - Capital de nível 1 + Capital de Nível - mínimo 8\% de APR (BACEN, 2013).

Segundo Pinheiro et al. (2015), além do Capital 1 e do Capital 2, estabeleceu que o Capital Regulatório da instituição deveria incluir: o Capital de Conservação e o Capital Contracíclico, ambos com2,5\% de APR Adicionais de Capital Principal. Assim, o Capital de Conservação e o Capital Contracíclico passaram a representar um ônus adicional para os bancos que teriam de dispor de uma maior quantidade e uma melhor qualidade de capital.

No Brasil os novos índices de capital foram estabelecidos pelo documento anexo ao comunicado $\mathrm{n}^{\circ}$ 20.615, de 2011, do Banco Central. A expectativa é de que os índices de exigência de requerimento de capital dentro dos padrões internacionais estabelecidos pelo Acordo de Basiléia III, se tornem congruentes com os nacionais.

Por sua vez Dantas et al. (2018) indicaram que não há evidências de que os bancos brasileiros utilizem a discricionariedade na constituição da PCLD para fins de gerenciamento de capital. Por outro lado, reforçaram as evidências de estudos anteriores, nacionais e internacionais, sobre o tema, no sentido de que as instituições utilizam essa discricionariedade na PCLD com o propósito de gerenciamento de resultados. Mesmo quando aplicado sobre as instituições financeiras consideradas "menos" capitalizadas, os testes também não confirmaram a hipótese de gerenciamento de capital. Esse importante estudo contribui para as discussões em curso no âmbito dos reguladores contábeis e bancários sobre o modelo atual de provisão para perdas de crédito.

\section{Metodologia}

O presente estudo é desenvolvido em duas principais etapas, uma explanação sobre o sistema financeiro: Regulação Bancária; Capital e Risco, os Acordos de Basiléia I, II e III, as regras de constituição das Provisões para Créditos de Liquidação Duvidosa e o Gerenciamento de resultado. Adicionalmente, foram apresentados alguns pontos específicos das regulamentações estabelecidas pelo CMN, ou seja, a Resolução $\mathrm{n}^{\mathbf{0}}$ 2.682/1999 e as normas internacionais de divulgação financeira (IFRS) com pontos que tratam da perda esperada recuperação e perda por redução no valor recuperável em entidades do setor financeiro.

A segunda parte do trabalho consiste em avaliar, se a PCLD é "gerenciada” em função da manutenção do Índice de Basiléia. Os dados analisados foram de 115 instituições financeiras bancárias atuantes no país, extraídos do sitio do BACEN (Despesa de Devedores Duvidosos; Ativo Total; Operações de Crédito; Passivo não Circulante; Patrimônio líquido; Lucro líquido) e corresponderam a um total de 846 observações. O período de estudo foi de 7 anos (2010 a 2016), onde se analisou o comportamento da PCLD, do Patrimônio Líquido sobre o Ativo Total e o Índice de Basiléia. Foi escolhido como marco o ano de 2010 devido ao fato de já se terem passado 2 anos da crise financeira de 2008, período também que coincide com os ajustes às novas regras estabelecidas pelo Comitê de Supervisão Bancária de Basiléia (Basel Committee on Banking Supervision - BCBS), o Acordo de Basiléia III, ano de 2011. E como prazo final o ano de 2016, por serem os últimos dados divulgados pelo BACEN, contemplando os ajustes propostos pelo acordo. Lembrando que os dados sofrerão evolução até 2019.

A análise foi realizada sob a ótica do plano de contas do COSIF, sendo que se optou pelo uso de valores a preços correntes, não ajustados pela inflação para preços constantes, devido ao fato dos dados serem recentes e não sofrerem grandes impactos da inflação como no período do 
plano real, ou seja, períodos anteriores a 1996.

\subsection{Modelo Proposto}

O modelo aplicado nesse estudo foi adaptado do modelo utilizado por Fuji (2004), que pesquisou o gerenciamento de resultados em bancos com enfoque na conta Provisões para Créditos de Liquidação Duvidosa (PCLD), onde foram encontradas evidências de que os bancos utilizam de gerenciamento em suas demonstrações de resultado. Para alcançar os objetivos traçados aplicou-se a análise de regressão com base em um modelo econométrico com dados em pooled, que procurou verificar a existência de relação estatisticamente significativa entre as variveis de interesse das instituições financeiras e o nível de provisão para créditos de liquidação duvidosa (PCLD)

Modelo que é clássico, sendo referenciado por diversos autores da literatura contábil brasileira, entre eles: Martinez (2006), Santos (2007), Goulart (2007), Macedo (2016), dentre outros, como forma de testar o gerenciamento de resultados, capital ou ambos em instituições financeiras bancárias. Em sua análise utilizou técnicas estatísticas de correlação e regressão linear múltipla, como também um modelo para estimar o componente discricionário de uma conta específica. Estimou e analisou a relação entre um item específico, a PCLD e o resultado contábil, ou seja, o lucro líquido, identificando evidências de suavização de resultados.

Corrobora com outros autores como Moyer (1990); Sholeset al. (1990) e Beatty et al. (1995); Kim e Kross (1998); Bischoff (2012), dentre outros, no sentido de que a apropriada formação da PCLD assume extrema relevância para se manter a saúde financeira das instituições, pois permite dimensionar o risco de suas operações de crédito e consequentemente o risco de sua carteira.

Sendo assim, neste trabalho foi utilizado o seguinte modelo econométrico adaptado de Fuji (2004) e Goulart (2007), cuja equação é:

PCLD $i, t=\alpha 0+\alpha 1$ Resi, $t+\alpha 2$ Pi,t $+\alpha 3$ Op. Cred $i, t+\alpha 4$ Req.Capi $t+\alpha 5$ ReqCapi, $t *$ dentro $+\varepsilon$

Onde:

- PCLD $i, t=$ a despesas com provisão para créditos de liquidação duvidosa da instituição $i$ no ano $t$; As variáveis independentes:

- Resi,t = o resultado das despesas de PCLD somadas ao Lucro Líquido, excluindo as despesas com IR imposto de Renda;

- $\mathrm{P} i, t=\mathrm{o}$ saldo do Passivo não Circulante;

- Op. Credi,t= são as operações de crédito e arrendamento mercantil de curto e longo prazo (BACEN) da instituição i no ano t;

- Req.Capi,t= Patrimônio Líquido PL dividido pelo Ativo Total AT;

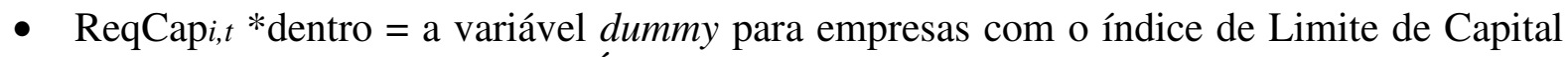
acima de 12\%, LimCap> 0,12 (Índice de Basiléia exigível 11\%).

- $\alpha 0=$ a constante (intercepto)

Optou-se pela análise estatística através da Regressão Linear Múltipla para verificar se a variável PCLDi,t está sendo explicada pelo requisito de capital. Foi incluída a variável de interação ReqCapi,t $*$ dentro a fim de considerar se a instituição se encontra dentro dos padrões BACEN e de que forma isto influencia na variação da PCLDi,t.

Assim, como no modelo de Fuji (2004), foi incluído o Resi,t que é o resultado antes da PCLDi, $t$; o Pi,t, passivo não circulante e as OpCredi,t, operações de crédito. Onde as variáveis resultado, passivo não circulante e operações de crédito servem para explicar a PCLD. Propôs-se a existência de uma relação direta entre o volume das operações de crédito, do passivo não 
circulante e a PCLD. Ainda, a hipótese de que o Resi,t, (o resultado antes da PCLD) seria capaz de influenciar o montante das provisões. Sendo que, se observada a existência de uma relação significativa entre estas duas variáveis, isto seria um indicativo de que algo além da qualidade do crédito, ou do montante das operações de crédito estaria influenciando a PCLD.

Assim, a expressão $\alpha 1$ Resi, $t$ estaria representando uma motivação para o gerenciamento de capital e a utilização de um income smoothing, um income increase ou um decrease. $\mathrm{O}$ gerenciamento de capital, também é testado ainda, pelos coeficientes requisito de capital (ReqCapi,t) e o Índice de Basiléia (ReqCapi, $t$ *dentro). Estes coeficientes seriam responsáveis por sinalizar se os requisitos de capital estão dentro dos padrões e se influenciam no montante de PCLD. Logo, o modelo utilizado neste estudo é abrangente e inova em relação ao de Fuji (2004) ao incorporar o $\alpha 4$ Req.Capi, $t+\alpha 5$ ReqCapi, $t *$ dentro.

\section{Análise dos Resultados}

Esta análise se restringiu aos dados coletados do sistema bancário brasileiro, sendo o período da amostra de 2010 a 2016. Os dados da análise foram extraídos do balancete de instituições financeiras bancárias no país, seguindo o Plano Contábil das Instituições Financeiras (COSIF) divulgadas pelo BACEN. Para fins deste estudo foram coletados dados referentes a PCLD; ao Lucro Líquido; ao Passivo não Circulante, as Contas Receber de Curto Prazo e Longo Prazo; do Patrimônio Líquido e do Ativo Total correspondendo a uma média de 115 instituições por ano.

Observou-se que a quantidade de amostra em cada ano alterou-se devido ao fato de que nem todas as instituições divulgaram as informações necessárias para essa análise ao BACEN, sendo estas excluídas da análise. A coluna observações indica o número de instituições encontradas em cada ano pesquisado, totalizando o valor de 805 em 7 anos.

Tabela 1 - Matriz de Correlação

\begin{tabular}{r|cccccc}
\hline & PCLDi, $t$ & Resi, $\boldsymbol{t}$ & Pi, $\boldsymbol{t}$ & OpCrédi, $\boldsymbol{t}$ & ReqCapi, $\boldsymbol{\text { ReqCapi, } \boldsymbol { t } * \text { dentro }}$ \\
\hline CLD $\boldsymbol{i}, \boldsymbol{t}$ & 1 & & & & & \\
Resi, $\boldsymbol{t}$ & 0,948 & 1 & & & & \\
Pi, $\boldsymbol{t}$ & 0,788 & 0,8977 & 1 & & & \\
OpCrédi, $\boldsymbol{t}$ & 0,7544 & 0,8457 & 0,9839 & 1 & & \\
ReqCapi, $\boldsymbol{t}$ & $-0,1476$ & $-0,1625$ & $-0,1852$ & $-0,1793$ & 1 & \\
ReqCapi, $\boldsymbol{t}^{*}$ dentro & $-0,1664$ & $-0,1818$ & $-0,2081$ & $-0,1957$ & 0,9797 & 1 \\
\hline
\end{tabular}

Fonte: Dados da pesquisa

Legenda: PCLDi,t: Provisão para Créditos de Liquidação Duvidosa; Resi,t: resultado Lucro Líquido somado a PCLD; Pi,t é o passivo não-circulante; OpCrédi,t: são as operações de crédito e arrendamento mercantil de curto e longo prazo; ReqCapi,t é a exigência de capital; ReqCapi,t *dentro: é a variável dummy para empresas com índice requerimento de capital acima de $12 \%$.

Evidencia-se que por sua natureza e definição a PCLD atua como uma medida de risco da carteira de crédito podendo influenciar o Resultado diminuindo ou aumentando-o. Observa-se, assim, a partir da matriz de correlação apresentada, que há uma relação positiva e significativa entre a variável Provisão para Créditos de Liquidação Duvidosa e o Resultado, correspondendo ao valor de 0,948 , significativo para a amostra. Havendo aumento do Resultado a tendência da provisão é aumentar, lembrando que neste caso o Resultado é computado antes da provisão. Assim, se uma instituição financeira atinge um Resultado maior ela tende a aprovisionar mais de forma a gerenciá-lo. E analogamente, tem-se que um aumento no Resultado, implica num aumento de provisão, que por sua vez, decorre do aumento das Operações de Crédito, que aumentam o Resultado e de novo provocam aumento da PCLD.

Verifica-se que entre as variáveis PCLD e o Passivo Não Circulante; e, entre a PCLD e a 
Operações de Crédito existe uma correlação positiva, porém com uma significância forte, os índices foram respectivamente, 0,788 e 0,7544. Considerando a relação existente entre a PCLD e o Passivo Não Circulante, uma possível explicação, seria que na medida em que há aumento do Passivo Não Circulante, há a assunção de um endividamento maior com capital de terceiros. E, assim, a instituição precisaria, portanto, assumir uma postura mais restritiva, assumindo uma maior aversão ao risco, recorrendo a um maior aprovisionamento de PCLD considerando suas Operações de Crédito. E desta forma, acaba eventualmente realizando maiores provisões para fazer frente a uma eventual insolvência para cobertura de seu Passivo Não circulante.

Já as Operações de Crédito e PCLD, como já dito, anteriormente, a correlação é positiva, quanto maior o montante de uma, maior será o montante da outra. A PCLD irá acompanhar naturalmente a evolução das Operações de Crédito. O banco, ao realizar um volume maior de Operações de Crédito em relação a seus Ativos Totais terá, portanto, uma maior PCLD. Já com relação a PCLD, o Requerimento de Capital e o Requerimento de Capital Dentro, a relação foi negativa e com baixo nível de correlação, os índices apresentados foram de -0,1476 e -0,1664. Considerando-se o Requerimento de Capital, tratado nesta análise como sendo o Patrimônio Líquido/Ativo Total, quando se aumenta a PCLD, ocorre um efeito marginal, ou seja, há a diminuição do Lucro Líquido. Havendo, portanto, tendência de redução do PL, que por si só, já seria suficiente reduzir o Requisito Capital.

Desta forma, quando a PCLD se apresenta mais elevada, os indicadores de Requerimento de Capital tendem a ser mais baixos, tendo em vista a redução do Patrimônio Líquido em virtude, naturalmente, da queda na receita do Lucro Líquido. Esse efeito é amenizado pelo fato de que a PCLD, reduz também o Ativo, porém, sua implicação sobre o Lucro Líquido e o Patrimônio Líquido, se apresenta mais forte indicando um sinal negativo.

O Requerimento de Capital Dentro, considerando neste caso, os bancos com Índice de Basiléia acima de $12 \%$. Índice considerado como satisfatório para este estudo, proporcionando certo conforto por estar dentro das exigências, e acima do recomendado atualmente de $11 \%$ que seria limítrofe podendo despertar a atenção da autoridade reguladora sobre situação financeira da instituição. Pela análise, se observa que quando há aumento de PCLD, em função das mesmas consequências apontadas para Requerimento de Capital, a tendência é que esse indicador venha a cair em virtude de que um aumento na PCLD, se repercute sobre o Lucro Líquido e logo, reduzem o Patrimônio Líquido. Assim, a PCLD é positivamente correlacionada com todas as variáveis, com exceção do Requerimento de Capital e do Requerimento de Capital Dentro que variam em sentido inverso.

Com relação às outras variáveis, a correlação com Resultado e Passivo Não Circulante; e entre Resultado e as Op. de Crédito, são positivas apresentando elevado grau de significância, com índices respectivamente de 0,8977e 0,8457. Logo, Resultado, o Passivo Não Circulante e Operações de Crédito aumentam a PCLD também. Entre o Resultado e as variáveis Requerimento de Capital e Requerimento de Capital Dentro a relação apresentou-se como negativa e com grau baixo de correlação, correspondendo aos índices de -0,1625 e -0,1818. Resultado negativamente correlacionado, variando em sentido contrário.

Quanto a análise a partir da Tabela 2 utilizou-se como forma de estimativa regressão linear múltipla, MQO (Mínimos Quadrados Ordinários) para eliminar problemas de heterocedasticidade, consistência e correlação serial. Nesse modelo de regressão, os coeficientes angulares são constantes ao longo do tempo e entre os indivíduos, e o coeficiente de intercepto varia de acordo com os indivíduos e tempo.

Embora não documentados nas tabelas, para assegurar a robustez das estatísticas, foram realizados testes adicionais, dentre os quais cabe destacar: i. teste de normalidade de Jarque-Bera (JB), indicando que os resíduos têm distribuição normal; ii. teste de Fator Inflação da Variância (FIV) que apresentou valores elevados próximos a 4,000, entretanto inferiores aos limites que levariam a caracterizar um grave problema de multicolinearidade, inobstante o uso de variáveis de 
relativa colinearidade e iii. teste de Breusch-Godfrey (BG), apurando não existir autocorrelação entre os resíduos.

Tabela 2 - Regressão Linear Múltipla - (MQO)

\begin{tabular}{r|ccccr}
\hline PCLDi, $\boldsymbol{t}$ & Coeficiente & $\mathbf{t}$ & p-valor & \multicolumn{2}{c}{ [Intervalo de 95\% de Conf.] } \\
\hline Resi, $\boldsymbol{t}$ & 0.9149711 & 19,61 & $0.000^{*}$ & 0,8233698 & 1.006 .572 \\
$\mathbf{P i} \boldsymbol{t} \boldsymbol{t}$ & $-0,0150087$ & $-6,21$ & $0.000^{*}$ & $-0,0197508$ & $-0,0102666$ \\
OpCréditoi, $\boldsymbol{t}$ & 0,0223802 & 5,36 & $0.000^{*}$ & 0,0141767 & 0,0305837 \\
ReqCapi,t & 22872,46 & 0,08 & 0.933 & $-512417,6$ & 558162,5 \\
ReqCapi, $\boldsymbol{t}^{*}$ dentro & $-116314,2$ & $-0,45$ & 0.655 & $-626836,2$ & 394207,9 \\
Constante & 30808,98 & 1,94 & 0.052 & -2.944 .652 & 61912,43 \\
\hline
\end{tabular}

Fonte: Dados da pesquisa.

Legenda: PCLDi,t: Provisão para Créditos de Liquidação Duvidosa; Resi,t: PCLD somada ao Lucro Líquido; Pi,t é o passivo não-circulante; OpCréditoi,t: são as operações de crédito e arrendamento mercantil de curto e longo prazo; ReqCapi,té a exigência de capital; ReqCapi, $t *$ dentro: é a variável dummy para empresas com índice requerimento de capital acima de $12 \%$.

*p<0,001 significância a $1 \%$.

\section{Discussão dos Resultados}

Os resultados expostos no item anterior apresentaram uma relação significativa entre as variáveis Provisões para Créditos de Liquidação Duvidosa, Resultado, Passivo não Circulante e as Operações de Crédito. A significância está dentro do intervalo de $1 \%$ o que se caracteriza como de grande relevância para a amostra. Concluiu-se que quanto maior for a PCLD, maior se apresentará o Resultado, o sinal entre as variáveis foi positivo.

Observou-se que a PCLD exerce um papel de atenuante e de mitigadora do Resultado, reduzindo assim sua variabilidade. Tal mecanismo implica na indicação de que existe uma prática de income smoothing, o que apresentou coerência com a literatura estudada. Logo, o valor de 19,61 apresentados pela estatística t é compatível com o grau de significância desta variável para o modelo em análise, sendo que, o Resultado, para fins deste computo, representa o resultado antes da provisão. Com relação ao P, este, atua negativamente, reduzindo a PCLD. Quanto maior for a dívida do banco, ou seja, o valor de P, há uma tendência de que se reduza a PCLD.

Observa-se que esta disposição apresentada entre o Passivo Não Circulante e a consequente redução da PCLD, reforça a teoria da prática de gerenciamento de resultado. Neste caso, a instituição irá aprovisionar menos no intuito de reportar a percepção de um lucro maior para o período, atenuando o efeito de seu endividamento. Com essa atitude há uma atenuação da desconfiança do mercado com relação a seu nível ao seu nível de risco, dissipando a visão de um grau de alavancagem excessiva.

A variável Operação de Crédito apresenta sinal positivo, indicando também que quanto maior for o seu volume, maior será o valor de sua PCLD. Desta forma, quanto maior for o montante de crédito, maior também será o aprovisionamento que se tem que fazer se considerando também o nível de risco, classificação, já descrita anteriormente.

Porém, observou-se que as variáveis Requerimento de Capital e Requerimento de Capital Dentro, objeto principal deste estudo, em comparação com a PCLD, não se mostraram significativas. Portanto, a PCLD, não é explicada pelo volume ou pelo patamar de capital das instituições financeiras bancárias do Brasil.

O fato de se ter mais ou menos capital, se o banco está dentro ou fora do Índice de Basiléia, não seria peremptório para a determinação dos valores de PCLD. O Requerimento de Capital e Requerimento de Capital Dentro, definido como Índice de Basiléia, não influência a PCLD dentro do modelo proposto. Assim, os bancos não estariam, portanto, preocupados quando constituída sua PCLD, com o a exigência de Requerimento de Capital prevista na legislação. 


\section{Conclusão}

A partir da análise proposta com relação a provisão de créditos para liquidação duvidosa e os limites de solvências em instituições bancárias no Brasil, com base nos dados analisados se concluiu que, a variável dependente PCLD sofre influência de algumas variáveis do modelo, não influenciando, porém, o Índice de Basiléia, objeto deste estudo. No entanto, há que se considerar ainda, que além das variáveis estudadas, existem outros fatores preponderantes que influenciam as decisões dos bancos em manter ou não um nível de capital acima da exigência mínima de $11 \%$, o que não se caracterizam como objeto deste estudo. Porém, neste sentido, os bancos apresentam uma tendência em tentar equacionar o capital e risco de maneira a não impactar negativamente o Índice de Basiléia estabelecido pelo BACEN.

O estudo apresentou indícios de que a PCLD pode influenciar o Resultado, pois houve uma relação positiva entre as variáveis, um aumento no Resultado eleva a provisão, e assim vice-versa. Atingindo um resultado maior, a instituição, está propensa a aprovisionar mais, reforçando a presença de gerenciando de resultado. Quando o resultado (antes da PCLD) aumenta isto implica em aumento de PCLD, que por sua vez, é proveniente de aumento das Operações de Crédito.

A PCLD também demonstrou influenciar o Passivo não Circulante, caracterizando que quando esse aumenta, pode estar ocorrendo um maior endividamento com capital de terceiros. Já quando se compara o fluxo inverso Passivo não Circulante e PCLD, quanto maior for a dívida do banco, há uma tendência de que se reduza a PCLD, reforçando a teoria da prática de gerenciamento de resultado com o intuito de reportar a percepção de um lucro maior visando atenuar o efeito de seu endividamento. Quando a PCLD se apresenta mais elevada, os indicadores de Requerimento de Capital apresentam tendência de serem mais baixos, pois o Patrimônio Líquido se reduz, provavelmente em virtude, de queda na receita com o Lucro Líquido. Efeito esse que é amenizado pelo fato de que a PCLD, também reduz o Ativo. Observou-se que quando há aumento de PCLD, em razão das mesmas causas para Requerimento de Capital, a tendência é que esse indicador venha a cair, aumento na PCLD se repercute sobre o Lucro Líquido reduzindo o Patrimônio.

Então a PCLD exerce papel de mitigadora do Resultado reduzindo sua variabilidade, indicando que existe uma prática de income smoothing, sendo coerente com a literatura estudada. Logo, os dados referentes ao Resultado, ao Passivo não Circulante e as Operações de Crédito demonstraram interferir no resultado da PCLD, positiva ou negativamente, dependendo do interesse dos gestores. Porém, observou-se que o Requerimento de Capital não foi influenciado pela PCLD. E as instituições que mantiveram Requisito de Capital acima dos limites determinados pelo Índice de Basiléia de $11 \%$, não sofreram influência dos montantes de provisão da PCLD. Não revelando o que se era esperado para a análise. O modelo não evidenciou que o volume de PCLD tenha explicações pelo montante ou pelo patamar de capital das instituições financeiras bancárias do Brasil. O fato de um banco ter mais ou menos capital, se o Índice de Basiléia está dentro ou acima, não seria fator determinante para a constituição da PCLD.

Dessa forma, os bancos não estariam preocupados com a exigência de Requerimento de Capital prevista na legislação quando do tratamento de sua PCLD. Não se verificou que a PCLD sofra gerenciamento de resultado em decorrência de influências do Requerimento de Capital, o que seria nosso objetivo de estudo. Através do modelo proposto neste estudo, se pretendia verificar se o resultado antes da PCLD e o Índice de Basiléia exerciam influências sobre a variável PCLD. No entanto, na prática se observa que a PCLD no momento em que oscila nas demonstrações financeiras dos bancos, podem propiciar de certa forma ajustes aos requisitos mínimos exigidos, pois atuam em variáveis que o compõem, mesmo não sendo influenciada por ele. A não variabilidade dos lucros, proporcionada por meio do gerenciamento do resultado, pode em dados momentos, ser capaz de permitir a preservação do capital dos bancos. Observou-se também por meio das literaturas pesquisadas, que as alterações promovidas pelos Acordos de Basiléia I, II e III contribuíram na promoção de um controle maior e estabilidade para o mercado bancário. 
Atuando no sentido de proporcionar maior transparência na divulgação das informações contábeis, buscando auxiliar na divulgação de informações mais seguras para os investidores e usuário das informações contábeis.

Por fim, conclui-se que a PCLD e os limites de solvência das instituições financeiras bancárias no Brasil são de grande importância para a estabilidade econômica do mercado financeiro e requerem acompanhamento e supervisão constante dos reguladores. Alterações significativas em seus patamares podem prejudicar diversos setores econômicos do país.

A pesquisa apresentou como limitação básica o universo das instituições financeiras bancárias brasileiras, tendo em vista que alguns conglomerados que não divulgaram suas Demonstrações Contábeis em alguns anos no período de 2010 a 2016 no sitio do BACEN. A amostra utilizada na pesquisa e as informações disponibilizadas abrangeram apenas 805 observações de 115 empresas bancárias o que pode ser considerado como limitações do estudo, pois podem distorcer os resultados em função de participarem do setor financeiro. Considerou-se também como limitação do estudo o não escalonamento das instituições por meio de seu ativo, embora se reconheça que o fato pode induzir a erro de mensuração, optou-se por deixar os valores em termos absolutos a exemplo dos estudos desenvolvidos por Rodrigues, 2013; Cerqueira, 2009 e Cardoso, 2016.

Para estudos futuros, referentes ao tema, se sugerem que sejam verificadas as possíveis implicações em se manter o Índice de Basiléia (IB) em valores superiores ou inferiores em consideração, a fatores de exposição a riscos. E assim, investigar, se uma capitalização maior proporcionaria um nível de risco menor. Outra possibilidade seria tecer uma mesma análise considerando, porém, os dados sob a ótica da IFRS se estabelecendo uma comparação escalonada por níveis e portes das instituições situadas no Brasil.

\section{Referências}

ANDRADE, C. R. Basiléia III: uma análise das novas recomendações do comitê de supervisão bancária da Basiléia sobre o setor financeiro brasileiro. 2014. Dissertação. Universidade Federal do Rio Grande do Sul. Disponível em: http://www.lume.ufrgs.br/handle/10183/116636. Acesso em: 10 de abr., 2017.

ARAÚJO, L.A D.; NETO, P. M. J.; LINHARES, F. Capital, risco e regulação dos bancos no Brasil. Pesquisa e Planejamento Econômico, v. 38, n. 3, 2008.

BACEN - Banco Central do Brasil. Resolução CMN n. 4.192. Brasília, DF: 2013.

BCBS. Basel Committee on Banking Supervison. Basel II: international convergence of capital measurement and capital standards: a revised framework - comprehensive version. Basel: Bank for International Settlements. June, 2006. Disponível em: http://www.bis.org/publ/bcbs128.pdf. Acesso em: 10 de abr., 2017.

BISCHOFF, Lissandra; LUSTOSA, Paulo Roberto Barbosa. PCLD e Suavização de Resultados em Instituições Financeiras no Brasil. 2012. Tese (Doutorado). Universidade Federal do Rio Grande do Norte.

BIKKER, J. A.; METZEMAKERS, P.A.J. Bank provisioning behavior and procyclicality. Journal of International Financial Markets, Institutions and Money, v. 15, n. 2, p. 141-157, 2005. https://doi.org/10.1016/j.intfin.2004.03.004

BEATTY, A.; CHAMBERLAIN, S. L; MAGLIOLO, J. Managing Financial Reports of 
Commercial Banks: The Infuences of Taxes, Regulatory Capital and Earnings. Journal of Accounting Research. v. 33, n. 2, p. 231-261, 1995. https://doi.org/10.2307/2491487

BORNEMANN, S.; KICK, T.; MEMMEL, C.; PFINGSTEN, A. Are banks using hidden reserves to beat earnings benchmarks? Evidence from Germany. Journal of Banking \& Finance, v. 36, n. 8, p. 2403-2415, 2012. https://doi.org/10.1016/j.jbankfin.2012.05.001

BRITO, G. A.; ASSAF NETO, A. Modelo de classificação de risco de crédito de empresas. Revista Contabilidade \& Finanças. USP. São Paulo, v. 19, n. 46, p.1829, Jan./abr. 2008. https://doi.org/10.1590/S1519-70772008000100003

BRITTO, S.A.; RODRIGUES, A.; COSTA, J. A. V. Divulgação nos relatórios dos bancos públicos brasileiros: análise das recomendações do Pilar 3 do Acordo de Basiléia 2. Revista de Administração Pública, v. 47, n. 6, p. 1329-1358, 2013. https://doi.org/10.1590/S003476122013000600001

CARNEIRO, F. L. Modelagem de Risco de Crédito de Portfólio: Implicações para a Regulamentação sobre Requerimento de Capital de Instituições Financeiras. 2002. Dissertação (Mestrado) Fundação Getúlio Vargas, FGV/EAESP- São Paulo. Disponível em: http://bibliotecadigital.fgv.br/dspace/handle/10438/4793. Acesso em: 28 de dez., 2016.

CARDOSO, F. A. Perdas Esperadas e Versus Perdas Incorridas: Qual Modelo Reflete mais apropriadamente as Perdas Efetivas dos Bancos Brasileiros? 2016. Monografia Universidade de Brasília. Disponível em:

http://bdm.unb.br/bitstream/10483/14223/1/2016_FernandoAugustoCardoso_tcc.pdf. Acesso em: 07 de mar. 2017.

CARVALHO, Fernando José Cardim. Inovação financeira e regulação prudencial: da regulação de liquidez aos acordos da Basiléia. Regulação financeira e bancária. São Paulo: Atlas, 2006.

CAVALLO, M.; MAJNONI, G. Do banks provision for bad loans in good times? Empirical evidence and policy implications. Springer, 2002.

CERQUEIRA, D. R. C. Créditos e Inadimplência no Sistema Financeiro Nacional. Nota Técnica: Boletim Conjuntural, nº 42, jul/1998.

COLLINS, J. H.; SHACKELFORD, D. A.; WAHLEN, J. M. Bank Differences in the Coordination of Regulatory Capital, Earnings, and Taxes. Journal of Accounting Research, v. 33, n. 2, 1995. https://doi.org/10.2307/2491488

COMITÊ DE PRONUNCIAMENTOS CONTÁBEIS. CPC 00 R1: Estrutura Conceitual para Elaboração e Divulgação de Relatório Contábil-Financeiro. Brasília, 2011.

COSTA, J. N. Acordo de Basiléia: Impacto no comportamento das Instituições Financeiras Brasileiras. Brasília, DF: 2004. Dissertação (Mestrado em Economia de Empresas) Universidade Católica de Brasília. Disponível em: https://bdtd.ucb.br. Acesso em: 25 de fev., 2017.

ERNST \& YOUNG; FIPECAFI. Manual de normas internacionais de contabilidade: IFRS 
versus normas brasileiras. 2. ed. São Paulo: Atlas, 2010

DANTAS, J. A.; CARVALHO, J. A.; PEREIRA, J. V. As Instituições Financeiras Brasileiras usam a PCLD para Gerenciamento de Capital?. Enfoque Reflexão Contábil, v. 37, n. 2, p. 127$140,2018$.

FERNANDES, D. T. M.; PONTE, V. M. R.; MOURA, H. J. D.; LUCA, M. M. M. D.; OLIVEIRA, M. C. The impacts of resolution n. 2.682 and programs to restructure the National Financial System on the provision level of the banking sector's credit portfolio. Revista Contabilidade \& Finanças, v. 19, n. 47, p. 44-55, 2008. https://doi.org/10.1590/S151970772008000200005 .

FRIEDMAN, R. M.; ROBERTS, W. W. The Carry-Forward Provision and Management of Bank Reserves. The Journal of Finance, v. 38, n. 3, p. 845-855, 1983. https://doi.org/10.1111/j.15406261.1983.tb02505.x

FUJI, A. H. Gerenciamento de resultados contábeis no âmbito das instituições financeiras atuantes no Brasil. Dissertação de Mestrado. Universidade de São Paulo, São Paulo, 2004.

FURTADO, A.L.M. Acordo da Basiléia: Um estudo sobre as suas influencias e implementação no Sistema Financeiro Brasileiro. 2005. Monografia. Universidade Federal de Santa Catarina. Disponível em https://repositorio.ufsc.br/handle/123456789/121830. Acesso: em 25 de fev., 2017.

GOULART, A. M. C. Gerenciamento de resultados contábeis em instituições financeiras no Brasil. Tese (Doutorado). Universidade de São Paulo, São Paulo, 2007.

GREENAWALT, M. B.; SINKEY JR, J. F. Bank loan-loss provisions and the incomesmoothing hypothesis: an empirical analysis, 1976-1984. Journal of Financial Services Research, v. 1, n. 4, p. 301-318, 1988. https://doi.org/10.1007/BF00235201

INTERNATIONAL ACCOUNTING STANDARDS COMMITTEE FOUNDATION. Guidance on Implementing International Accounting Standard 39, Financial Instruments:

Recognition and Measurement. International accounting standards board, 2003.

KIM, M.; KROSS, W. The Impact of the 1989 Change in Bank Capital Standards on Loan Loss Provision and Loan Write-offs. Journal of Accounting and Economics, v. 25, p. 69-99, 1998. https://doi.org/10.1016/S0165-4101(98)00015-9

KOEHN, M.; SANTOMERO, M. Regulation of bank capital and portfolio risk. Journal of Finance, v. 35, p. 1.235-1.244, 1980. https://doi.org/10.2307/2327096

LAEVEN, L.; MAJNONI, G. Loan loss provisioning and economic slowdowns: too much, too late? Journal of Financial Intermediation, v. 12, n. 2, p. 178-197, 2003. https://doi.org/10.1016/S1042-9573(03)00016-0

MACEDO, M. A. S.; KELLY, V. L. A. Gerenciamento de resultados em instituições financeiras no Brasil: uma análise com base em provisões para crédito de liquidação duvidosa. Revista Evidenciação Contábil \& Finanças, v. 4, n. 2, p. 82-96, 2016. https://doi.org/10.18405/RECFIN20160206 
MARQUES, Luís Fernando Bicca. Gerenciamento do Risco de Crédito: cálculo do risco de crédito para a carteira de um banco de varejo. 2002. Dissertação (Mestrado)-Universidade do Rio Grande do Sul. Porto Alegre.

MARQUES, José Augusto Veiga da Costa; BRITTO, Andréia da Silva; Adriano, RODRIGUES; Divulgação nos relatórios dos bancos públicos brasileiros: análise das recomendações do Pilar 3 do Acordo de Basiléia 2. Revista de Administração Pública -RAP, v. 47, n. 6, 2013. https://doi.org/10.1590/S0034-76122013000600001

MARTIN, N. C. Os controles internos no contexto bancário. São Paulo, SP: Fipecafi, 2006.

MARTINEZ, L. A. Detectando Earnings management no Brasil: estimando os accruals discricionários. Rev. Contab. Finanç., São Paulo, v. 19, n. 46, p. 7-17, 2008. https://doi.org/10.1590/S1519-70772008000100002

MARTINEZ, L. A. Minimizando a variabilidade dos resultados contábeis: estudo empírico do income smoothing no Brasil. Revista Universo Contábil, v. 2, n. 1, p. 09-25, 2006. http://dx.doi.org/10.4270/ruc.20062

MOYER, S. Capital Adequacy Ratio Regulations and Accounting Choices in Commercial Banks. Journal of Accounting and Economics, v. 13, p. 123-154, jul., 1990. https://doi.org/10.1016/0165-4101(90)90027-2

MICCA, P. M. Observações sobre crédito e preferência de liquidez de grandes bancos no Brasil (1997-2002). Pontifícia Universidade Católica de São Paulo. São Paulo, 2003.

NIYAMA, Jorge Katsumi. Constituição da provisão para créditos de liquidação duvidosa de bancos e demais instituições financeiras-principais alterações introduzidas pelo conselho monetário nacional e o efeito nas demonstrações contábeis. ConTexto, v. 1, n. 1, 2001.

NIYAMA, J.K; GOMES, A. L. O. Contabilidade de Instituições Financeiras. 3. ed. São Paulo: Atlas, 2005.

PINHEIRO, F. A. P.; SAVÓIA, J. R. F.; SECURATO, J. R. Basiléia III: Impacto para os Bancos no Brasil. Revista Contabilidade \& Finanças, v. 26, n. 69, p. 345-361, 2015.

https://doi.org/10.1590/1808-057x201500720

PUGA, F. P. Sistema Financeiro Brasileiro: Reestruturação recente, comparações internacionais e vulnerabilidade à crise cambial. Rio de Janeiro, 03/1999. Disponível em: http://www.bndes.gov.br/SiteBNDES/export/sites/default/bndes_pt/Galerias/Arquivos/conhecim ento/td/Td-68.pdf. Acesso em: 21 de abr., 2017.

RODRIGUES, R. N. O Acordo da Basiléia um estudo da Adequação de Capital nas instituições financeiras, 1998. Tese (Doutorado). Universidade de São Paulo, São Paulo. Disponível em: http://www.teses.usp.br/teses/disponiveis/12/12136/tde-12122007185158/en.php. Acesso em: 03 de mar., 2017.

SANTOS, E. C. Capital regulatório e gerenciamento de resultados nas instituições financeiras que atuam no Brasil. 2007. 128 f. Dissertação (Mestrado em Ciências Contábeis)- 
Programa de Pós-Graduação em Ciências Contábeis da Fundação Instituto Capixaba de Pesquisas em Contabilidade, Economia e Finanças-FUCAPE, Vitória.

SCHOLES, M. S.; WILSON, G. P.; WOLFSON, M. A. Tax Planning, Regulatory Capital. Planning, and Financial Reporting Strategy for Commercial Banks. Review of Financial Studies, p. 625-650, 1990. https://www.jstor.org/stable/2962118

SCHLOTTFELDT, Cristiane Lauer. Exigência mínima de capital e rentabilidade: uma análise empírica dos bancos brasileiros. 2004 Dissertação (Mestrado) Universidade Federal do Rio Grande do Sul. Disponível em: http://www.lume.ufrgs.br/handle/10183/4304. Acesso em: 03 de mar., 2017.

SHRIEVES, Ronald E; DAHL, Drew. Discretionary Accounting and the Behavior of Japanese Banks under Financial Duress. Journal of Banking and Finance, v. 27, p. 1219-1243, 2003. https://doi.org/10.1016/S0378-4266(02)00252-2

SILVA, J. M. B. Impactos dos modelos de perda esperada e de perda incorrida nas carteiras de crédito dos bancos brasileiros. 2013. Disponível em: http://bdm.unb.br/10483/11819. Acesso em: 03 de mar., 2017.

SOARES, R. P. Evolução do Crédito de 1994 a 1999: Uma Explicação. Texto para discussão n. 808. Instituto de Pesquisa Econômica Aplicada. Ministério do Planejamento, Orçamento e Gestão. Brasília, 2001.

TRAPP, A. C.G; CORRAR, L. J. Avaliação e Gerenciamento do Risco Operacional no Brasil: Análise de Caso de uma Instituição Financeira de Grande Porte. Revista de Contabilidade e Finança. USP, São Paulo, Jan./Abr., 2005. https://doi.org/10.1590/S1519-70772005000100002 